Article

\title{
Removal of Cadmium from Contaminated Water Using Coated Chicken Bones with Double-Layer Hydroxide (Mg/Fe-LDH)
}

\author{
Saif S. Alquzweeni ${ }^{1, *}$ and Rasha S. Alkizwini ${ }^{2}$ \\ 1 Civil Engineering Department, Faculty of Engineering, University of Babylon, Babel 51002, Iraq \\ 2 Environmental Engineering Department, Faculty of Engineering, University of Babylon, Babel 51002, Iraq; \\ eng.rasha.salah2020@gmail.com \\ * Correspondence: saifalquzweeni2020@gmail.com
}

Received: 24 June 2020; Accepted: 10 August 2020; Published: 17 August 2020

\begin{abstract}
Occurrence of heavy metals in freshwater sources is a grave concern due to their severe impacts on public health and aquatic life. Cadmium $\left(\mathrm{Cd}^{2+}\right)$ is one of the most dangerous heavy metals, and can cause serious diseases even at low concentrations. Hence, a wide range of treatment technologies exist, such as nanofiltration and biological reactors. In this context, the present investigation aims at the development of a new adsorption medium, made from chicken bones coated with iron (Fe) and magnesium $(\mathrm{Mg})$ hydroxides, to remove cadmium from water. This novel chicken bone functional substance was manufactured by applying layered double hydroxides (LDH) into the chicken bones. Initially, the new adsorption medium was characterized using Fourier-transform infrared spectroscopy (FTIR technology), then it was applied to remove cadmium from water under different conditions, including $\mathrm{pH}$ of water (3-7.5), agitation speed (50-200 rpm), adsorbent dose (1-20 g per $100 \mathrm{~mL})$, and contact time (30-120 min). Additionally, the reaction kinetics were studied using a pseudo-first order kinetic model. The results obtained from the present study proved that the new adsorption medium removed $97 \%$ of cadmium after $120 \mathrm{~min}$ at an agitation speed of $150 \mathrm{rpm}$, $\mathrm{pH}$ of 5, and adsorption dose of $10 \mathrm{~g}$ per $100 \mathrm{~mL}$. The results also showed that the new adsorption medium contains a significant number of functional groups, including hydroxyl groups. According to the outcomes of the kinetic study, the mechanism of removing metal is attributed to surface precipitation, ion exchange, complexation, hydrogen binding between pollutants, and the LDH-chicken bone substance.
\end{abstract}

Keywords: adsorption of cadmium; cadmium; heavy metal; raw waste bones

\section{Introduction}

The availability of freshwater is a major concern currently due to the increase in the production of wastewater, including that from municipal, agricultural and industrial sources, and because of the rapid increase in the global population and its associated demand for a significant amount of freshwater to meet daily needs [1-3]. The production rate of wastewater has increased due to the substantial rise in industrial output [4-6], while increasing water demand and climate change have limited the availability of freshwater $[7,8]$. Industrial wastewater is considered as the most serious source of water pollution as it contains a broad range of hazardous contaminants, such as biological pollutants $[9,10]$, nutrients [11], geosmin [12], organic matter [13], dyes [14,15], and heavy metals [16,17]. Among these, heavy metals pollution is a grave concern for the water industry as heavy metals are toxic even at low concentrations [18-20], and their separation from wastewater is a significant problem [21,22]. For instance, the literature shows that heavy metals are responsible for a broad range of diseases, such as Alzheimer's, liver failure, kidney failure, and damage to the nervous system [23,24]. In addition, 
when industrial wastewater containing heavy metals is discharged directly into municipal wastewater treatment plants, significant damage can occur in the biological treatment units, and the produced sludge could be toxic $[14,25]$. The occurrence of metal ions in water has motivated researchers to develop effective and economically efficient treatment methods to remediate water from these hazardous pollutants. According to published studies, at present the most commonly used methods for the remediation of water from heavy metals are oxidation-reduction by zero-valent $\mathrm{Fe}$, precipitation by apatite, and ion exchange and adsorption by various industrial and natural materials, such as clay, natural zeolite, animal bones, sawdust, and agricultural products [26].

Animal bones are a type of biomass with no economic value as solid waste; however, when used as raw materials in char manufacture, their economic value is significantly increased [27,28]. Utilizing these materials as char is a sustainable method to minimize the substantial amount of solid waste from bones produced in meat processing, hospitality facilities (such as restaurants and hotels), and poultry houses. This is particularly beneficial due to the expensive and complex management required for solid wastes [29-31].

In this context, the present study examines the possibility of recycling chicken bones for use in water treatment by coating the bones with iron and magnesium oxides. This new adsorption medium was applied to remove cadmium from a synthetic water sample. Thus, this adsorption medium could be an eco-friendly and economically efficient alternative to the current methods for removal of heavy metals from water.

\section{Materials and Methods}

\subsection{Materials}

As mentioned previously, chicken bones were selected as the adsorbent material due to their wide availability at almost negligible cost. Samples of raw waste material were collected from local sites (poultry houses, butchery shops, and restaurants), in Babylon city, Iraq. The waste material was manually sorted to separate bones; then further processing was carried out to remove fat and skin from the separated bones. The cleaned bones were carefully washed, and subjected to several cycles of boiling and washing with tap water to ensure that all fats residue was removed. Then, the bones were air-dried and ground in two steps (manually and using a heavy-duty ball grinder (type: DECO-PBM-V-2L-A)). The ground particles were sieved to group them into three ranges; $0.075-0.300 \mathrm{~mm}, 1.400-2.360 \mathrm{~mm}$, and $2.360-4.750 \mathrm{~mm}$. These ranges were selected to cover most of the studied sizes in the literature [32,33].

\subsection{Preparation of Coated Chicken Bones}

The co-precipitation method was used to prepare the layered double hydroxides (LDHs) at ambient temperature. The required solution was prepared by mixing various molar ratios of $\mathrm{Mg}\left(\mathrm{NO}_{3}\right)_{2} \cdot 6 \mathrm{H}_{2} \mathrm{O}$ and $\mathrm{FeCl}_{3} \cdot 6 \mathrm{H}_{2} \mathrm{O}$ (Mg:Fe of 1:1, 2:1, 3:1, and 4:1) with various quantities of chicken bone particles $(0.05$, $0.1,0.3,0.5$, and $1 \mathrm{~g}$ ) in $100 \mathrm{~mL}$ of deionized water. Then, $2 \mathrm{M}$ of $\mathrm{NaOH}$ and $0.2 \mathrm{M}$ of $\mathrm{Na}_{2} \mathrm{CO}_{3}$ were added to the solution and stirred for one hour to attain a $\mathrm{pH}$ of 7 . This step was followed by drying the obtained solids at a temperature of $80^{\circ} \mathrm{C}$ for $24 \mathrm{~h}$ [34]. The coated media was applied to remove cadmium $\left(\mathrm{Cd}^{2+}\right)$ ions from synthetic water.

The coated chicken bone particles were characterized using Fourier-transform infrared spectroscopy (FTIR).

\section{Adsorption Experiment}

Sets of batch adsorption experiments were undertaken to investigate the ability of the developed coated adsorbent to remediate water from $\mathrm{Cd}^{2+}$ considering the influences of the initial $\mathrm{pH}$ of the water, agitation rate, adsorbent doses, and contact time. In these batch experiments, different adsorbent doses $(0.1,0.3,0.6,0.9,1,5$, and $10 \mathrm{~g})$ were added to a constant volume of synthetic water $(100 \mathrm{~mL})$ 
that contained $20 \mathrm{mg} / \mathrm{L}$ of $\mathrm{Cd}^{2+}$ ions in a $250 \mathrm{~mL}$ flask. The latter was shaken for $3 \mathrm{~h}$ at a mixing speed of $150 \mathrm{rpm}$. Removal of $\mathrm{Cd}^{2+}$ was periodically checked at 5, 15, 30, 60, 90, 120, 150, 180, 210, and $240 \mathrm{~min}$ by taking a small volume of solution which was filtered using Whatman filter papers $(0.45 \mu \mathrm{m})$ and measured for $\mathrm{Cd}^{2+}$ concentration using an atomic absorption spectrophotometer (Norwalk, Connecticut).

Batch experiments were conducted using a solution with initial $\mathrm{pH}$ ranging between 3 and 7.5, because higher $\mathrm{pH}$ values can result in precipitation of cadmium [35]. The initial $\mathrm{pH}$ of the prepared samples was controlled using the required volumes of $0.1 \mathrm{M} \mathrm{HNO}_{3}$ or $\mathrm{NaOH}$.

Removal efficiency ( $\mathrm{R} \%$ ) and uptake of $\mathrm{Cd}^{2+}$ were calculated as follows [36-38]:

$$
\begin{gathered}
\text { Removal effciency }(\%)=\frac{\left(C D_{o}-C D_{e}\right)}{C D_{o}} \times 100 \\
\text { Uptake }(\mathrm{qe})=\frac{\left(C D_{o}-C D_{e}\right) V}{m}
\end{gathered}
$$

where $C D_{o}$ and $C D_{e}$ are the initial and equilibrium concentrations of $C d^{2+}(\mathrm{mg} / \mathrm{L})$, respectively, $m$ represents the mass of adsorbents $(\mathrm{g})$, and $V$ is the volume of solution $(\mathrm{mL})$.

\section{Results and Discussion}

\subsection{Characterization of the Coated Chicken Bone Particles Using FTIR}

The detected peaks of the FTIR spectra of the new adsorbent were $556-615 \mathrm{~cm}^{-1}$ and $960-1040 \mathrm{~cm}^{-1}$, indicating that the apatite phase was well-crystallized and characteristic; see Figure 1 . The bending modes of phosphates represent the sharp peaks of $553 \mathrm{~cm}^{-1}$, and the v3 vibration modes of phosphates groups were indicated by two peaks, namely $1044 \mathrm{~cm}^{-1}$ and $970 \mathrm{~cm}^{-1}$. The adsorption band at $1421 \mathrm{~cm}^{-1}$ was due to the mode of vibration of the carbonate groups. In isolated hydroxyapatite, three characteristic bands were indicated, namely $580 \mathrm{~cm}^{-1}$ anti-symmetric triply-degenerate (O-P-O) bent for $\mathrm{PO}^{3-}, 960 \mathrm{~cm}^{-1}$ symmetrical non-degenerate $(\mathrm{P}-\mathrm{O})$ stretch, and $966 \mathrm{~cm}^{-1}$ because of the triply-degenerate asymmetric $(\mathrm{P}=\mathrm{O})$ stretch. A peak of the non-degenerate distortion of $\mathrm{H}_{2}$ groups, such as $\mathrm{H}-\mathrm{PO}_{4}{ }^{2-}$ and $\mathrm{H}-\mathrm{PO}_{3}$, was observed at $1288 \mathrm{~cm}^{-1}$. It was also noted that the FTIR spectra for the coated adsorbent after the adsorption process showed a broad peak at $3373 \mathrm{~cm}^{-1}$. There are three potential reasons for the appearance of this broad peak; firstly, the $\mathrm{O}-\mathrm{H}$ bond of the adjacent layers; secondly, the stretching vibration of the -OH interlocked with the inter-lamellar water; and thirdly, the physically adsorbed water.

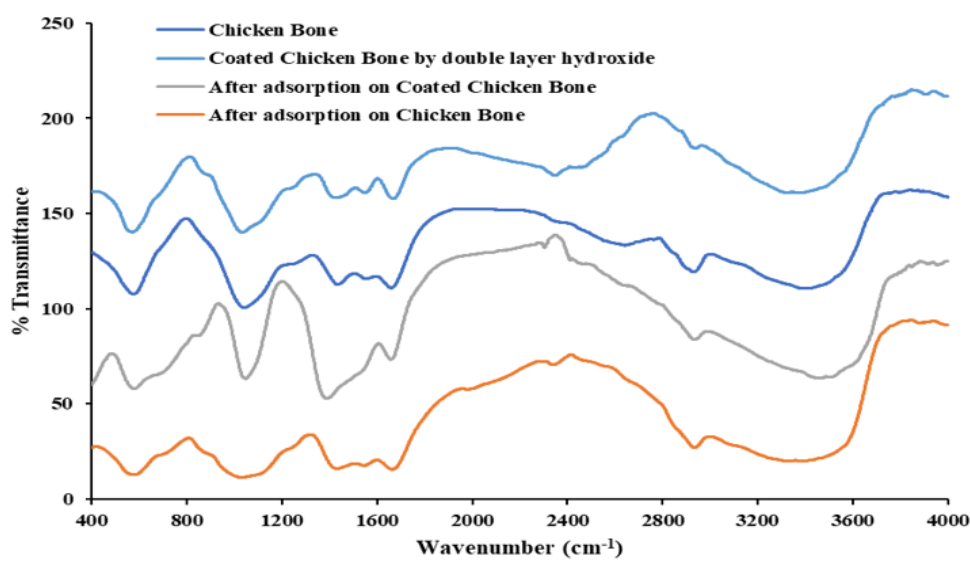

Figure 1. FTIR spectra of coated and uncoated chicken bone particles.

The vibrations of both metal-O and O-metal-O are usually associated with the peak closest to $553 \mathrm{~cm}^{-1}$ [39]. In comparison with the coated adsorbent, it was noted that sorbent had a shifted peak at 
$1348 \mathrm{~cm}^{-1}$. This shift in the peak occurred as a result of the in-plane vibration band of the $\mathrm{CO}_{3}{ }^{2-}$ and the stretch absorption band that indicates the successful enhancement of the coated adsorbent. Additionally, Figure 1 depicts the new peaks for the chicken bone/LDH and sorption chicken bone/LDH specimens, which appeared to be strengthening at 557, 1447, 1664, and $3425 \mathrm{~cm}^{-1}$. After the impregnation of $\mathrm{Mg}-\mathrm{Fe}$ layered double hydroxides (Mg-Fe LDH), the -OH stretching peak strengthened, but after the sorption of $\mathrm{Cd}^{2+}$, it was significantly weakened. These peaks considerably altered with the occurrence of the black shift afterwards the saturation of $\mathrm{Mg}$-Fe $\mathrm{LDH}$ and the adsorption of $\mathrm{Cd}^{2+}$, which proved that $\mathrm{Cd}^{2+}$ sorption was significantly influenced by the coating hydroxides.

\subsection{Effects of $\mathrm{Mg} / \mathrm{Fe}$ Molar Ratio}

Different $\mathrm{Mg} / \mathrm{Fe}$ molar ratios ( 1 to 4 ) were used to examine their effects on the adsorption of $\mathrm{Cd}^{2+}$ by the new coated adsorbent. The outcomes of the experiments proved that the highest sorption capacity of $\mathrm{Cd}^{2+}$ ions was achieved at an $\mathrm{Mg} / \mathrm{Fe}$ ratio of 3; see Figure 2. This proved that the sorption performance of the $\mathrm{Mg} / \mathrm{Fe}-\mathrm{LDH}$ for removing $\mathrm{Cd}^{2+}$ ions was enhanced with the increase in $\mathrm{Mg}$. Thus, subsequent experiments were undertaken at an $\mathrm{Mg} / \mathrm{Fe}$ ratio of 3 .

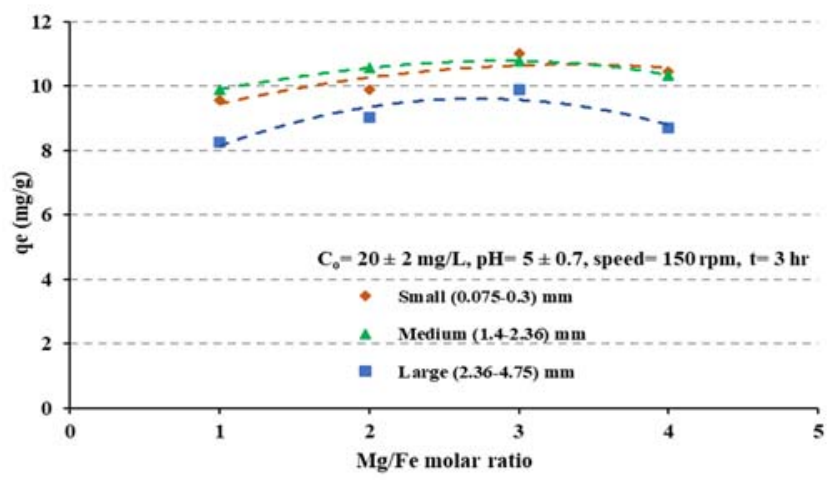

Figure 2. Variation of $\mathrm{Cd}^{2+}$ adsorption with the $\mathrm{Mg} / \mathrm{Fe}$ molar ratios.

\subsection{Batch Experiments}

The following batch experiments were undertaken to observe the influence of contact time, adsorbent dosages, $\mathrm{pH}$ of the solution, sizes of particles, and agitation speed on $\mathrm{Cd}^{2+}$ removal by both coated and uncoated adsorbents.

\subsubsection{Influence of Contact Time}

Influence of contact time on the ability of both coated and uncoated chicken bone particles to remove $\mathrm{Cd}^{2+}$ ions from water was explored by adding $1 \mathrm{~g}$ of each adsorbent into a $250 \mathrm{~mL}$ flask containing $100 \mathrm{~mL}$ of $\mathrm{Cd}^{2+}$ solution. Coarse $(2.360-4.750 \mathrm{~mm})$, medium $(1.400-2.360 \mathrm{~mm})$, and fine $(0.075-0.3 \mathrm{~mm})$ particles of each adsorbent were used in these experiments. Figure 3 depicts the removal of $\mathrm{Cd}^{2+}$ by both coated and uncoated chicken bone particles. It can be observed that two phases were involved in the metal sorption: the rapid sorption phase that involves passive surface reactions, such as chemical complexations (reaction between $\mathrm{Cd}^{2+}$ ions and anion hydroxides forming the metal-ligand complex), or electrostatic sorption onto the surface of adsorbents [34,40]. In this rapid phase, a considerable rise in $\mathrm{Cd}^{2+}$ removal was observed with the increase of contract time. This rapid phase was followed by a decrease in the removal of $\mathrm{Cd}^{2+}$. The decline in sorption could be related to the reduction in the availability of vacant sorption sites on the surfaces of coated or uncoated adsorbents. The outcomes of the experiments indicated that minimizing the particle size of the adsorbents was beneficial for $\mathrm{Cd}^{2+}$ removal; it was observed that the fine particles of both coated and uncoated particles provided better and faster removal of $\mathrm{Cd}^{2+}$ ions. The explanation for this enhancement in $\mathrm{Cd}^{2+}$ removal is the increase in the surface area of the particles (number of sorption sites) with the decrease in the particle sizes. Additionally, equilibrium status was attained after $60 \mathrm{~min}$ 
using the coated chicken bone particles, but $120 \mathrm{~min}$ were needed to attain equilibrium status using the uncoated chicken bone particles. Generally, the best removal of $\mathrm{Cd}^{2+}$ using the coated adsorbents was 98\%, which was reached after 60 min; using uncoated adsorbents it was 93\%, which was reached after $120 \mathrm{~min}$.
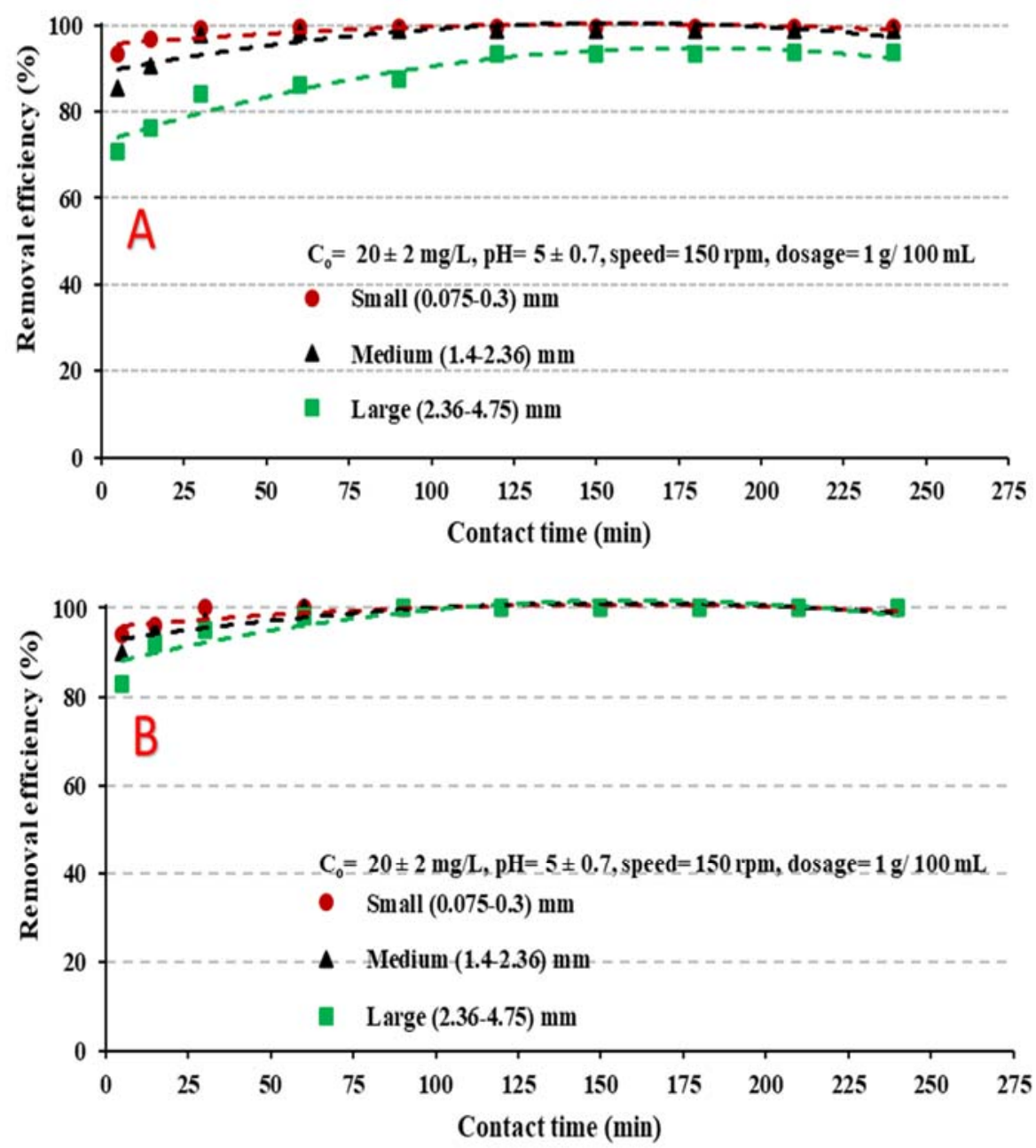

Figure 3. Variation of $\mathrm{Cd}^{2+}$ removal with contact time using: (A) Uncoated chicken bone particles, and (B) coated chicken bone particles.

\subsubsection{Influence of Agitation Speed}

Agitation speed is one of the most important parameters in the sorption processes because it makes the solution uniform and promotes efficient mass transfer, increases the potential contact between the $\mathrm{Cd}^{2+}$ ions and the binding sites on the surfaces of adsorbents, and reduces the film resistance related to the stationary fluid layer that represents an obstacle to mass transfer [41]. Thus, the effect of agitation speed on $\mathrm{Cd}^{2+}$ removal by both coated and coated particles was examined in this study at six agitation speeds, ranging from 0 (no agitation) to $250 \mathrm{rpm}$. The results (see Figure 4) confirmed that both high and low speeds were not useful for $\mathrm{Cd}^{2+}$ removal; low speeds do not provide enough contact between the pollutant and the binding sites, thus limiting the removal efficiency and mass transfer [41], and high agitation speeds result in breaking the newly developed bonds between the sorbate and the sorbent, and consequently decrease the removal of the targeted pollutant [42]. The results of this study showed that moderate agitation speeds provide good contact between the sorbate and the sorbent, and minimize the resistance for mass transfer, which results in good removal efficiency of pollutants. Thus, in the present study, an agitation speed of $150 \mathrm{rpm}$ was used in subsequent experiments. 

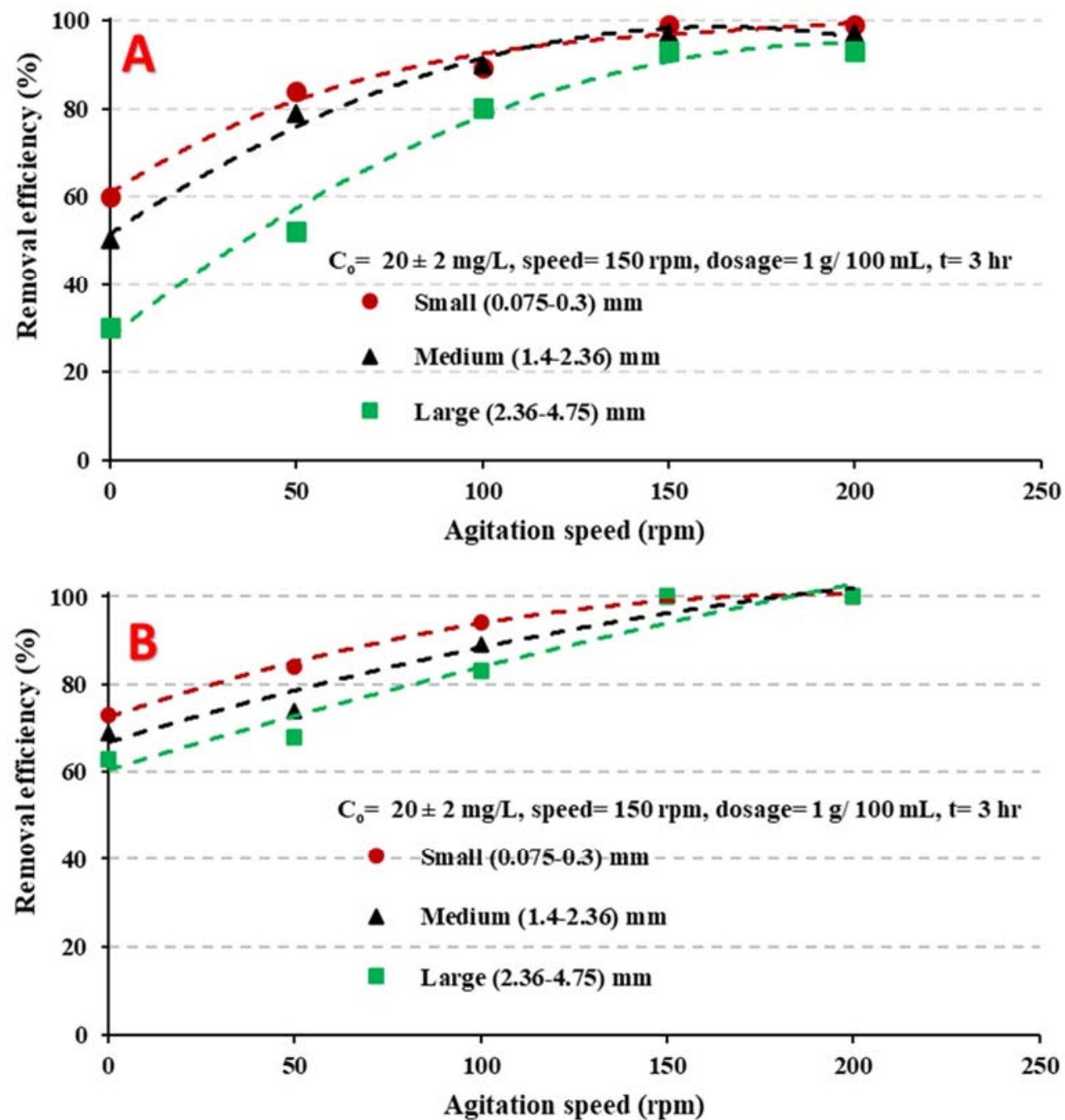

Figure 4. Variation of $\mathrm{Cd}^{2+}$ removal with the agitation speeds using: (A) Uncoated chicken bone particles, and (B) coated chicken bone particles.

\subsubsection{Influence of Initial $\mathrm{pH}$}

According to a previous study [42], the initial $\mathrm{pH}$ of solutions plays a substantial role in sorption processes as it influences key parameters, including the ionization degree, ion speciation, and the surface charge of the sorbent. The influence of the initial $\mathrm{pH}$ on $\mathrm{Cd}^{2+}$ removal by coated and uncoated adsorbents was explored at various values of $\mathrm{pH}$, ranging from 3 to 7.5. According to the outcomes of the present study, increasing the $\mathrm{pH}$ of the solution from 3 to 7.5 was highly beneficial for the removal of $\mathrm{Cd}^{2+}$ from water; see Figure 5. The noted decrease in $\mathrm{Cd}^{2+}$ removal at an acidic $\mathrm{pH}$ level could be related to the accumulation of the large number of hydrogen ions $\left(\mathrm{H}^{+}\right)$on the surface of adsorbents, which resisted the binding between the binding sites and $\mathrm{Cd}^{2+}$ ions. It may also be due to the ability of hydrogen ions to occupy the binding sites on the surfaces of the sorbents, thus preventing or minimizing the sorption of $\mathrm{Cd}^{2+}$ ions [43]. With the increase of $\mathrm{pH}$ to 7.5 , more $\mathrm{OH}^{-}$ions were generated, accelerating the formation of the insoluble cadmium complex $\left(\mathrm{Cd}(\mathrm{OH})_{2}\right)$, and thus leading to precipitate $\mathrm{Cd}^{2+}$ and consequently enhancing removal efficiency. Additionally, it is believed that at $\mathrm{pH} 7.5$ both $\mathrm{K}^{+}$and $\mathrm{Ca}^{+2}$ ions are released from the bones, and replaced by $\mathrm{Cd}^{2+}$ [43]. The latter path of $\mathrm{Cd}^{2+}$ removal strengthens the theory that the exchange of ions is the mechanism of $\mathrm{Cd}^{2+}$ ion adsorption on the chicken bone particles. It was noted at a $\mathrm{pH}$ range of 5-7.5 that the coated chicken bone particles captured the greatest amount of $\mathrm{Cd}^{2+}$ in comparison with uncoated chicken bone particles. As shown in Figure 5, the best $\mathrm{Cd}^{2+}$ removal, of about $99 \%$, was achieved by the coated 
chicken bone particles at a $\mathrm{pH}$ range of $5-7.5$. Hence, a $\mathrm{pH}$ of 5 was adopted in the present study to undertake subsequent experiments.
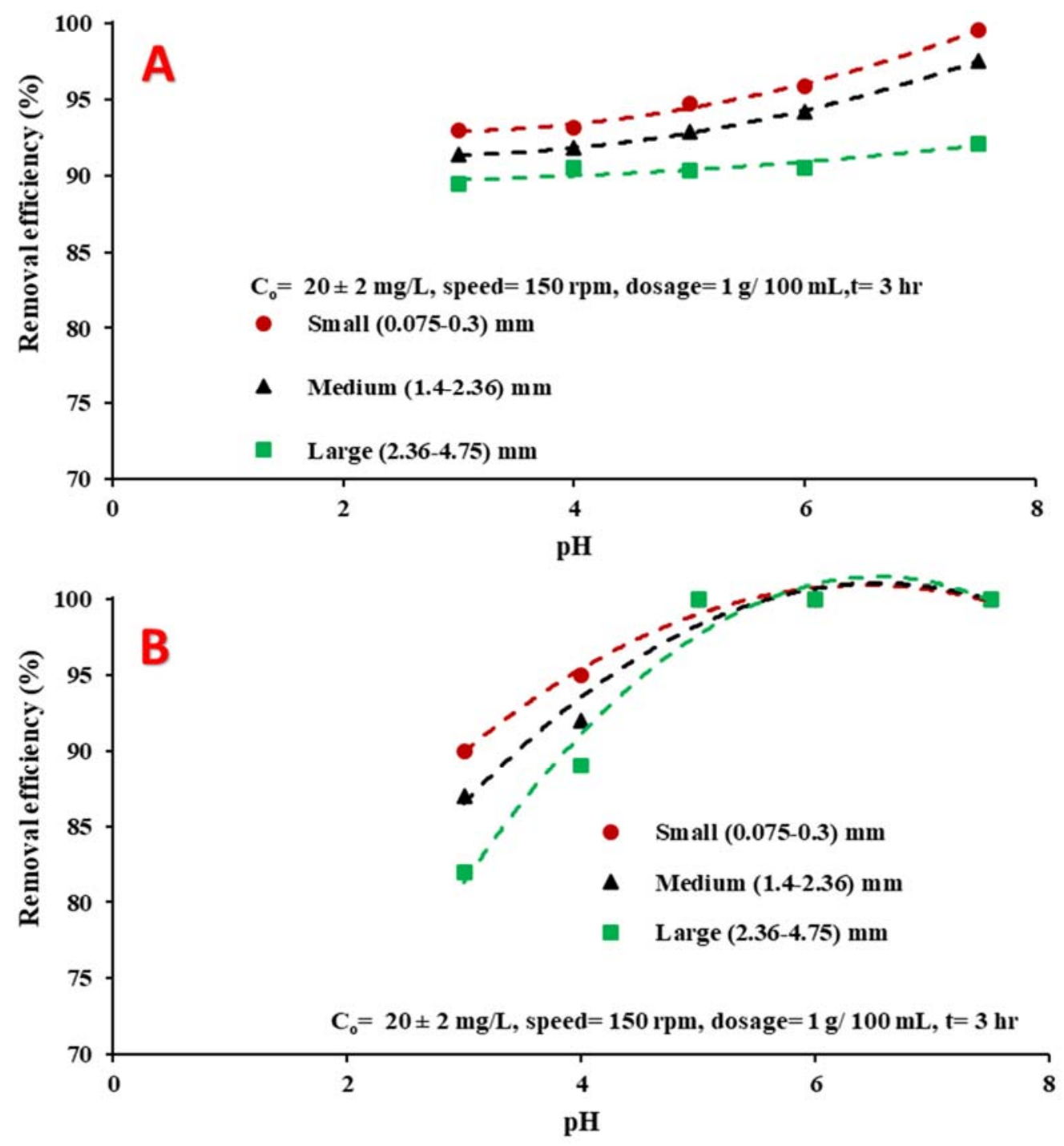

Figure 5. Variation of $\mathrm{Cd}^{2+}$ removal with the initial $\mathrm{pH}$ using: (A) Uncoated chicken bone particles, and (B) coated chicken bone particles.

\subsubsection{Influence of Adsorbent Doses}

The influence of adsorbents doses on $\mathrm{Cd}^{2+}$ removal was studied by varying the dosages of

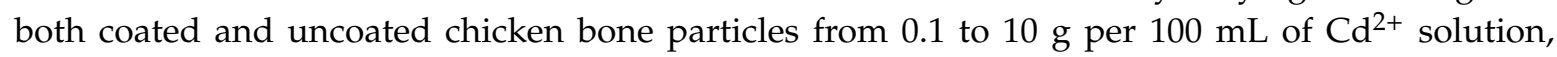
while maintaining the solution temperature, initial $\mathrm{pH}$, agitation speed, and contact time constant at $25 \pm 1^{\circ} \mathrm{C}, 5 \pm 0.7,150 \mathrm{rpm}$ and $3 \mathrm{~h}$, respectively. The influence of adsorbent doses on $\mathrm{Cd}^{2+}$ is illustrated in Figure 6, which indicates that changing the dose of uncoated chicken bone particles from 0.1 to $10 \mathrm{~g} / 100 \mathrm{~mL}$ substantially boosted the removal of $\mathrm{Cd}^{2+}$ from 63 to $97 \%$. In comparison, the removal percentage of the $\mathrm{Cd}^{2+}$ ions increased from 90 to $100 \%$ upon the variation of the coated chicken bone particles from 0.1 to $10 \mathrm{~g} / 100 \mathrm{~mL}$. This development in $\mathrm{Cd}^{2+}$ removal with the increase of the adsorbent doses is due to the substantial increment in the number of sorption sites, which thus led to greater removal efficiency [44]. Figure 6 also indicates that the relationships between the doses of coated and uncoated chicken bone particles and the removal of $\mathrm{Cd}^{2+}$ had the same trends despite a variation in the values of the best adsorbent dose that provided the greatest removal efficiency of the metal. 
Additionally, it is clear from Figure 6 that the removal of $\mathrm{Cd}^{2+}$ is influenced by the sorbent particle size; the smallest particle size $(0.075-0.3 \mathrm{~mm})$ removed approximately $5 \%$ more $\mathrm{Cd}^{2+}$ than the largest particle size $(2.36-4.75 \mathrm{~mm})$. As was mentioned previously, the high adsorption of $\mathrm{Cd}^{2+}$ at smaller particle size is attributed to the increase in the surface area of the adsorbent particles. In conclusion, the best $\mathrm{Cd}^{2+}$ removal was attained using an adsorbent dose of $10 \mathrm{~g} / 100 \mathrm{~mL}$ and small size adsorbent particles.
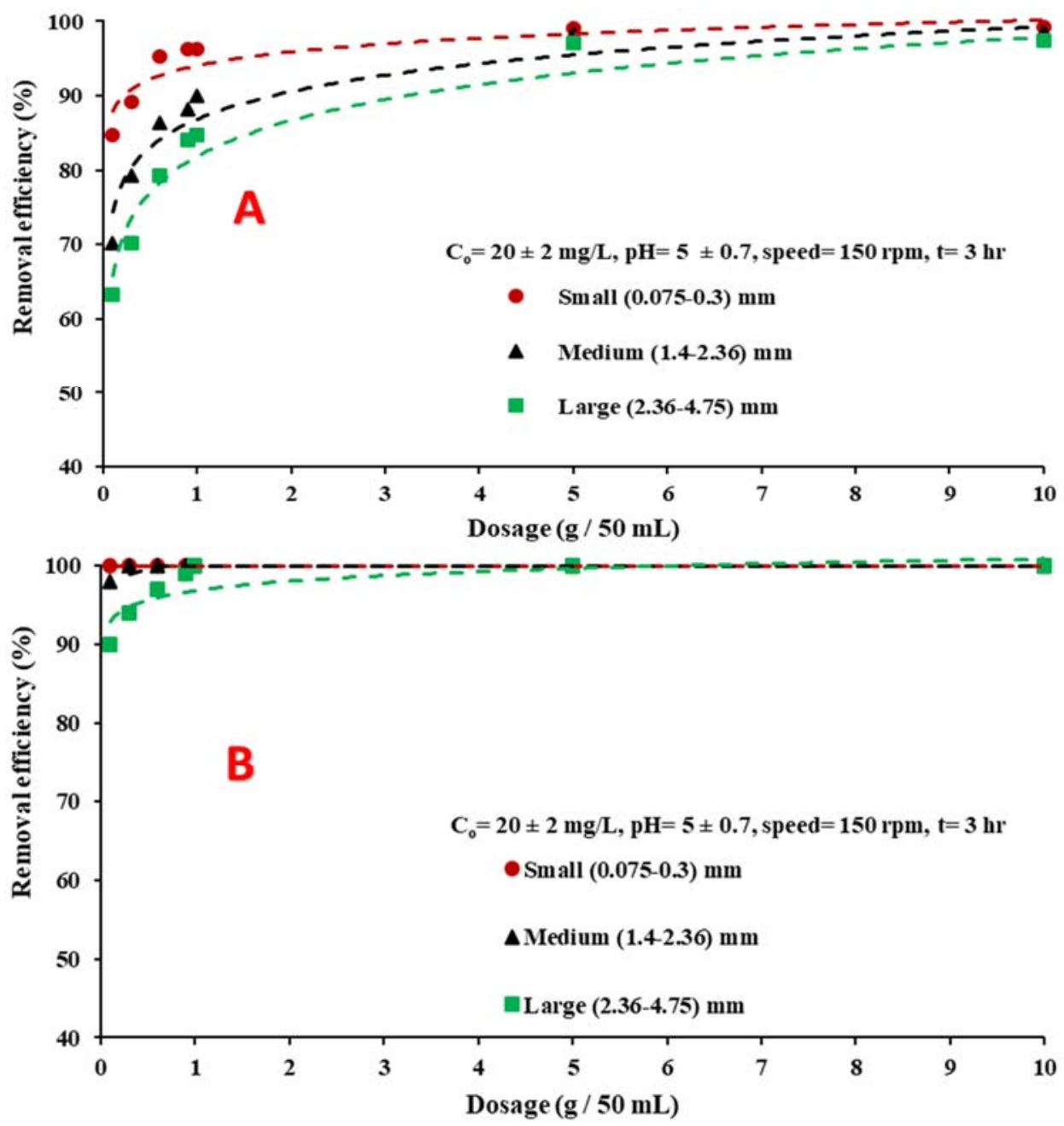

Figure 6. Variation of $\mathrm{Cd}^{2+}$ removal with the adsorbents doses using: (A) Uncoated chicken bone particles, and (B) coated chicken bone particles.

\subsection{Sorption Kinetics}

The sorption kinetics yields the uptake rate of the $\mathrm{Cd}^{2+}$ ions on both coated and uncoated chicken bone particles, and thereby identifies the equilibrium time. Kinetics modeling of sorption processes can be utilized to assess the mechanism of $\mathrm{Cd}^{2+}$ uptake on uncoated and coated sorbents. Additionally, studying the sorption kinetics provides valuable information on the rate of pollutant sorption from the liquid phase, which is necessary for the design of an effective sorption treatment system [45]. Typically, the process of sorption is modeled in accordance with the synthetic reaction onto the sorbent surface. Pseudo-first order and pseudo-second order equations are widely used for kinetic modeling of sorption processes [45]. Thus, these two models were employed in the current investigation to identify the sorption kinetics of $\mathrm{Cd}^{2+}$ sorption on both coated and uncoated adsorbents. 


\subsubsection{Pseudo-First Order Kinetic Model}

The pseudo-first order kinetic model is a widely used model in characterizing the sorption process of dissolved pollutants from the liquid phase. The general formula of this model is [46]:

$$
\frac{\mathrm{d} q}{\mathrm{~d} t}=k_{1}\left(q_{e}-q_{t}\right)
$$

where $q_{t}$ and $q_{e}$ represent the adsorbed amounts of $\mathrm{Cd}^{2+}(\mathrm{mg} / \mathrm{g})$ at any time and equilibrium time (minutes), respectively, while $k_{1}$ is the constant of the model (1/min).

The mentioned formula, Equation (3), is changed to the following form when it is integrated at the conditions of $q_{t}$ from 0 to the equilibrium time:

$$
\ln \left(q_{e}-q_{t}\right)=\ln q_{e}-k_{1}
$$

Writing the pseudo-first order kinetic model in a non-linear form yields the following formula, which represents the final form of the pseudo-first order kinetic model:

$$
q_{t}=q_{e} \times\left(1-\mathrm{e}^{-k_{1} \times t}\right)
$$

\subsubsection{Pseudo-Second Order Kinetic Model}

Some assumptions were made to enhance the outcomes of the pseudo-first order kinetic model, namely: (1) for all sorbents, the energy of sorption is the same, (2) the sorbates monolayer is attached to the surfaces of sorbents, and (3) the sorbed species have zero interaction with each other. These assumptions resulted in the development of the pseudo-second order kinetic model [47]:

$$
\frac{\mathrm{d} q}{\mathrm{~d} t}=k_{2} \times\left(q_{e}-q_{t}\right)^{2}
$$

where $k_{2}$ is the constant of the model (g/mg. minute). Integration of Equation (6) at $q_{t}$ from 0 to the equilibrium time yields the following equation [47]:

$$
\frac{1}{\left(q_{e}-q_{t}\right)}=\frac{1}{q_{e}}+k_{2} t
$$

The above formula could be simplified to the following form, which is the final form of the pseudo-second order model:

$$
q_{t}=\frac{\mathrm{t}}{\left(\frac{1}{k_{2} \times q_{e}^{2}}+\frac{t}{q_{e}}\right)}
$$

In the present investigation, it was noted that the pseudo-second order model best fitted the results of the uncoated and coated adsorbents, as shown in Table 1. The latter shows that the pseudo-second order model had the highest coefficient of determination $\left(\mathrm{R}^{2}\right)$ and closely matched the obtained results (Table 1 and Figure 7), which confirms its applicability for expressing $\mathrm{Cd}^{2+}$ sorption kinetics of coated and uncoated chicken bone particles. The pseudo-first order model performed better than the pseudo-second order model, based on the assumptions that the rate-controlling stage was chemisorption, including the valency force that occurred due to electrons exchange or sharing between the sorbate and the sorbent [48]. 
Table 1. Outcomes of the kinetics study.

\begin{tabular}{cccc}
\hline Model & Parameter & Uncoated Adsorbents & Coated Adsorbents \\
\hline \multirow{4}{*}{ Pseudo-first order } & $\mathrm{q}_{\mathrm{e}}$ & 1.965 & 2.139 \\
& $\mathrm{k}_{1}$ & 0.294 & 3.539 \\
& $\mathrm{R}^{2}$ & 0.964 & 0.968 \\
& $\mathrm{SSE}$ & 0.131 & 0.137 \\
\hline \multirow{4}{*}{ Pseudo-second order } & $\mathrm{q}_{\mathrm{e}}$ & 2.030 & 2.224 \\
& $\mathrm{k}_{2}$ & 0.261 & 0.404 \\
& $\mathrm{R}^{2}$ & 0.987 & 0.999 \\
& $\mathrm{SSE}$ & 0.047 & 0.006 \\
\hline
\end{tabular}

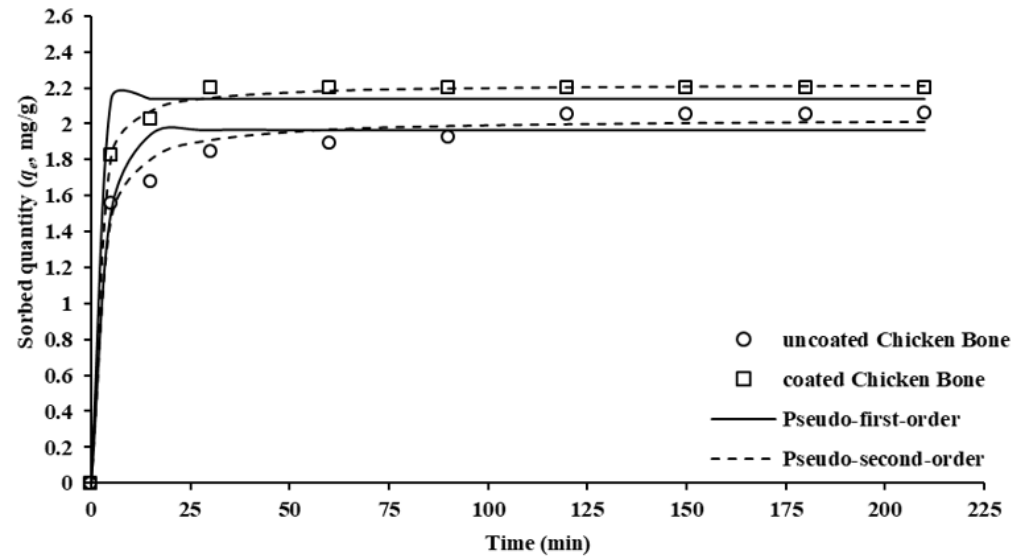

Figure 7. Kinetics study for sorption of $\mathrm{Cd}^{2+}$ using uncoated and coated chicken bone particles.

\section{Conclusions}

The present study focuses on the development of a new composite adsorbent by coating chicken bone particles with $\mathrm{Mg}$ and Fe hydroxides. The performance of this new adsorbent was validated by applying it to remove $\mathrm{Cd}^{2+}$ ions from synthetic water. The outcomes of this study proved the ability of the new adsorbent for metal ion removal. It was found that the performance of the new adsorbent was remarkably enhanced with the increase of the dose of adsorbent, contact time, and the initial $\mathrm{pH}$. Furthermore, it was found that minimizing the particle sizes enhanced the removal of $\mathrm{Cd}^{2+}$ ions. The results of the kinetics study confirmed the affinity between $\mathrm{Cd}^{2+}$ ions and the adsorbent particles. Results of the FTIR analysis indicated that the effective $\mathrm{Cd}^{2+}$ removal was due to the exchange of ions and the complexation of the hydroxyl group with heavy metal ions. Another factor possibly contributing to the removal of $\mathrm{Cd}^{2+}$ was the precipitation of metal hydroxides. In summary, the obtained results showed the developed adsorbent, which was made from waste materials, could be an economically efficient and eco-friendly alternative to the currently used adsorbents.

Author Contributions: Investigation, R.S.A.; Methodology, S.S.A. All authors have read and agreed to the published version of the manuscript.

Funding: This research received no external funding.

Acknowledgments: The researchers are grateful to the technicians at the laboratories of the University of Babylon for their help during this study. Additionally, the researchers are thankful to their collogues at the University of Babylon and at the British E-Systems Engineering Society for their help in proofreading this paper.

Conflicts of Interest: The authors declare no conflict of interest. 


\section{References}

1. Ahmad, S.; Majhi, P.K.; Kothari, R.; Singh, R.P. Industrial wastewater footprinting: A need for water security in Indian context. In Environmental Concerns and Sustainable Development; Springer: Berlin, Germany, 2020; pp. 197-212.

2. Hashim, K.S.; AlKhaddar, R.; Shaw, A.; Kot, P.; Al-Jumeily, D.; Alwash, R.; Aljefery, M.H. Electrocoagulation as an eco-friendly River water treatment method. In Advances in Water Resources Engineering and Management; Springer: Berlin, Germany, 2020; pp. 219-235.

3. Omran, I.I.; Al-Saati, N.H.; Hashim, K.S.; Al-Saati, Z.N.; Kot, P.; Khaddar, R.A.; Al-Jumeily, D.; Shaw, A.; Ruddock, F.; Aljefery, M.; et al. Assessment of heavy metal pollution in the Great Al-Mussaib irrigation channel. Desalin. Water Treat. 2019, 168, 165-174. [CrossRef]

4. Emamjomeh, M.M.; Mousazadeh, M.; Mokhtari, N.; Jamali, H.A.; Makkiabadi, M.; Naghdali, Z.; Hashim, K.S.; Ghanbari, R. Simultaneous removal of phenol and linear alkylbenzene sulfonate from automotive service station wastewater: Optimization of coupled electrochemical and physical processes. Sep. Sci. Technol. 2019, 2,1-11. [CrossRef]

5. Aljerf, L. High-efficiency extraction of bromocresol purple dye and heavy metals as chromium from industrial effluent by adsorption onto a modified surface of zeolite: Kinetics and equilibrium study. J. Environ. Manag. 2018, 225, 120-132. [CrossRef] [PubMed]

6. Abdulhadi, B.A.; Kot, P.; Hashim, K.S.; Shaw, A.; Khaddar, R.A. Influence of current density and electrodes spacing on reactive red 120 dye removal from dyed water using electrocoagulation/electroflotation (EC/EF) process. In Proceedings of the First International Conference on Civil and Environmental Engineering Technologies (ICCEET), Al-Najaf, Iraq, 23-24 April 2019; pp. 12-22.

7. Zubaidi, S.; Al-Bugharbee, H.; Ortega Martorell, S.; Gharghan, S.; Olier, I.; Hashim, K.; Al-Bdairi, N.; Kot, P. A Novel Methodology for Prediction Urban Water Demand by Wavelet Denoising and Adaptive Neuro-Fuzzy Inference System Approach. Water 2020, 12, 1628. [CrossRef]

8. Zubaidi, S.L.; Ortega-Martorell, S.; Al-Bugharbee, H.; Olier, I.; Hashim, K.S.; Gharghan, S.K.; Kot, P.; Al-Khaddar, R. Urban Water Demand Prediction for a City that Suffers from Climate Change and Population Growth: Gauteng Province case study. Water 2020, 12, 1885. [CrossRef]

9. Alattabi, A.W.; Harris, C.; Alkhaddar, R.; Alzeyadi, A.; Hashim, K. Treatment of Residential Complexes' Wastewater using Environmentally Friendly Technology. Procedia Eng. 2017, 196, 792-799. [CrossRef]

10. Hashim, K.S.; Ali, S.S.M.; AlRifaie, J.K.; Kot, P.; Shaw, A.; Al Khaddar, R.; Idowu, I.; Gkantou, M. Escherichia coli inactivation using a hybrid ultrasonic-Electrocoagulation reactor. Chemosphere 2020, 247, 125868-125875. [CrossRef]

11. Sun, D.; Hong, X.; Wu, K.; Hui, K.; Du, Y.; Hui, K. Simultaneous removal of ammonia and phosphate by electro-oxidation and electrocoagulation using $\mathrm{RuO}_{2}-\mathrm{IrO}_{2} / \mathrm{Ti}$ and microscale zero-valent iron composite electrode. Water Res. 2020, 169, 115239.

12. Ryecroft, S.P.; Shaw, A.; Fergus, P.; Kot, P.; Hashim, K.; Conway, L. A Novel Gesomin Detection Method Based on Microwave Spectroscopy. In Proceedings of the 12th International Conference on Developments in eSystems Engineering (DeSE), Kazan, Russia, 7-10 October 2019; pp. 429-433.

13. Al-Saati, N.H.; Hussein, T.K.; Abbas, M.H.; Hashim, K.; Al-Saati, Z.N.; Kot, P.; Sadique, M.; Aljefery, M.H.; Carnacina, I. Statistical modelling of turbidity removal applied to non-toxic natural coagulants in water treatment: A case study. Desalin. Water Treat. 2019, 150, 406-412. [CrossRef]

14. Hashim, K.S.; Al-Saati, N.H.; Alquzweeni, S.S.; Zubaidi, S.L.; Kot, P.; Kraidi, L.; Hussein, A.H.; Alkhaddar, R.; Shaw, A.; Alwash, R. Decolourization of dye solutions by electrocoagulation: An investigation of the effect of operational parameters. In Proceedings of the First International Conference on Civil and Environmental Engineering Technologies (ICCEET), Al-Najaf, Iraq, 23-24 April 2019; pp. 25-32.

15. Hashim, K.S.; Hussein, A.H.; Zubaidi, S.L.; Kot, P.; Kraidi, L.; Alkhaddar, R.; Shaw, A.; Alwash, R. Effect of initial $\mathrm{pH}$ value on the removal of reactive black dye from water by electrocoagulation (EC) method. In Proceedings of the 2nd International Scientific Conference, Al Diwaniyah, Iraq, 23-24 June 2019; pp. 12-22.

16. Hashim, K.S.; Shaw, A.; Al Khaddar, R.; Pedrola, M.O.; Phipps, D. Iron removal, energy consumption and operating cost of electrocoagulation of drinking water using a new flow column reactor. J. Environ. Manag. 2017, 189, 98-108. [CrossRef] 
17. Doggaz, A.; Attoura, A.; Mostefa, M.L.P.; Côme, K.; Tlili, M.; Lapicque, F. Removal of heavy metals by electrocoagulation from hydrogenocarbonate-containing waters: Compared cases of divalent iron and zinc cations. J. Water Process Eng. 2019, 29, 100796. [CrossRef]

18. Rahi, M.A.; Faisal, A.A.; Naji, L.A.; Almuktar, S.A.; Abed, S.N.; Scholz, M. Biochemical performance modelling of non-vegetated and vegetated vertical subsurface-flow constructed wetlands treating municipal wastewater in hot and dry climate. J. Water Process Eng. 2020, 33, 101003. [CrossRef]

19. Ogata, F.; Nagai, N.; Toda, M.; Otani, M.; Saenjum, C.; Nakamura, T.; Kawasaki, N. Removal of Arsenic (III) Ion from Aqueous Media Using Complex Nickel-Aluminum and Nickel-Aluminum-Zirconium Hydroxides. Water 2020, 12, 1697. [CrossRef]

20. Alkhudhiri, A.; Hakami, M.; Zacharof, M.-P.; Abu Homod, H.; Alsadun, A. Mercury, Arsenic and Lead Removal by Air Gap Membrane Distillation: Experimental Study. Water 2020, 12, 1574. [CrossRef]

21. Mohora, E.; Rončević, S.; Agbaba, J.; Zrnić, K.; Tubić, A.; Adžemović, M.; Dalmacija, B. Effects of combined Fe-Al electrodes and groundwater temperature on arsenic removal by electrocoagulation. Environ. Prot. Eng. 2019, 45, 5-18. [CrossRef]

22. Hashim, K.S.; Al-Saati, N.H.; Hussein, A.H.; Al-Saati, Z.N. An investigation into the level of heavy metals leaching from canal-dreged sediment: A case study metals leaching from dreged sediment. In Proceedings of the First International Conference on Materials Engineering \& Science, Istanbul, Turkey, 22-24 April 2018; pp. 12-22.

23. Bakulski, K.M.; Seo, Y.A.; Hickman, R.C.; Brandt, D.; Vadari, H.S.; Hu, H.; KyunPark, S. Heavy Metals Exposure and Alzheimer's Disease and Related Dementias. J. Alzheimer's Dis. 2020, 1, 1-28. [CrossRef]

24. Fu, X.; Li, L.; Yang, G.; Xu, X.; He, L.; Zhao, Z. Removal of Trace Thallium from Industrial Wastewater by Fe0-Electrocoagulation. Water 2020, 12, 163. [CrossRef]

25. Chamanchia, M.; Vaferib, B.; Jalili, I. A comparative experimental study of the removal of heavy metals using low cost natural adsorbents and commerical activated carbon. Int. J. 2012, 3, 55-60.

26. Shareef, K.M. Sorbents for contaminants uptake from aqueous solutions. Part I: Heavy metals. World J. Agric. Sci. 2009, 5, 819-831.

27. Tripathi, M.; Sahu, J.N.; Ganesan, P. Effect of process parameters on production of biochar from biomass waste through pyrolysis: A review. Renew. Sustain. Energy Rev. 2016, 55, 467-481. [CrossRef]

28. Skoulou, V.; Zabaniotou, A. Investigation of agricultural and animal wastes in Greece and their allocation to potential application for energy production. Renew. Sustain. Energy Rev. 2007, 11, 1698-1719. [CrossRef]

29. Abdulredha, M.; Rafid, A.; Jordan, D.; Hashim, K. The development of a waste management system in Kerbala during major pilgrimage events: Determination of solid waste composition. Procedia Eng. 2017, 196, 779-784. [CrossRef]

30. Abdulredha, M.; Al Khaddar, R.; Jordan, D.; Kot, P.; Abdulridha, A.; Hashim, K. Estimating solid waste generation by hospitality industry during major festivals: A quantification model based on multiple regression. Waste Manag. 2018, 77, 388-400. [CrossRef] [PubMed]

31. Arvanitoyannis, I.S.; Ladas, D. Meat waste treatment methods and potential uses. Int. J. Food Sci. Technol. 2008, 43, 543-559. [CrossRef]

32. Zhang, L.; Tang, S.; Jiang, C.; Jiang, X.; Guan, Y. Simultaneous and efficient capture of inorganic nitrogen and heavy metals by polyporous layered double hydroxide and biochar composite for agricultural nonpoint pollution control. ACS Appl. Mater. Interfaces 2018, 10, 43013-43030. [CrossRef]

33. Kizilkaya, B.; Tekınay, A.A. Utilization to remove $\mathrm{Pb}$ (II) ions from aqueous environments using waste fish bones by ion exchange. J. Chem. 2014, 739273, 1-12. [CrossRef]

34. Ahmed, D.N.; Naji, L.A.; Faisal, A.A.; Al-Ansari, N.; Naushad, M. Waste foundry sand/MgFe-layered double hydroxides composite material for efficient removal of Congo red dye from aqueous solution. Sci. Rep. 2020, 10, 1-12. [CrossRef]

35. Naji, L.A.; Jassam, S.H.; Yaseen, M.J.; Faisal, A.A.; Al-Ansari, N. Modification of Langmuir model for simulating initial $\mathrm{pH}$ and temperature effects on sorption process. Sep. Sci. Technol. 2019, 23, 1-8. [CrossRef]

36. Faisal, A.A.; Al-Wakel, S.F.; Assi, H.A.; Naji, L.A.; Naushad, M. Waterworks sludge-filter sand permeable reactive barrier for removal of toxic lead ions from contaminated groundwater. J. Water Process Eng. 2020, 33, 101112. [CrossRef] 
37. Hashim, K.; Kot, P.; Zubaid, S.; Alwash, R.; Al Khaddar, R.; Shaw, A.; Al-Jumeily, D.; Aljefery, M. Energy efficient electrocoagulation using baffle-plates electrodes for efficient Escherichia Coli removal from wastewater. J. Water Process Eng. 2020, 33, 101079-101086. [CrossRef]

38. Hashim, K.S.; Khaddar, R.A.; Jasim, N.; Shaw, A.; Phipps, D.; Kota, P.; Pedrola, M.O.; Alattabi, A.W.; Abdulredha, M.; Alawsh, R. Electrocoagulation as a green technology for phosphate removal from River water. Sep. Purif. Technol. 2019, 210, 135-144. [CrossRef]

39. Li, J.; Zhang, N.; Ng, D.H. Synthesis of a 3D hierarchical structure of $\gamma-\mathrm{AlO}(\mathrm{OH}) / \mathrm{Mg}-\mathrm{Al}-\mathrm{LDH} / \mathrm{C}$ and its performance in organic dyes and antibiotics adsorption. J. Mater. Chem. A 2015, 3, 21106-21115. [CrossRef]

40. Shen, Y.; Li, H.; Zhu, W.; Ho, S.-H.; Yuan, W.; Chen, J.; Xie, Y. Microalgal-biochar immobilized complex: A novel efficient biosorbent for cadmium removal from aqueous solution. Bioresour. Technol. 2017, 244, 1031-1038. [CrossRef]

41. Parvathi, K.; Nagendran, R.; Nareshkumar, R. Lead biosorption onto waste beer yeast by-product: A means to decontaminate effluent generated from battery manufacturing industry. Electron. J. Biotechnol. 2007, 10, 92-105. [CrossRef]

42. Znad, H.; Frangeskides, Z. Chicken drumstick bones as an efficient biosorbent for copper (II) removal from aqueous solution. Desalin. Water Treat. 2014, 52, 1560-1570. [CrossRef]

43. Al-Asheh, S.; Banat, F.; Mohai, F. Sorption of copper and nickel by spent animal bones. Chemosphere 1999, 39, 2087-2096. [CrossRef]

44. Amarasinghe, B.; Williams, R.A. Tea waste as a low cost adsorbent for the removal of $\mathrm{Cu}$ and $\mathrm{Pb}$ from wastewater. Chem. Eng. J. 2007, 132, 299-309. [CrossRef]

45. Puranik, P.; Modak, J.; Paknikar, K. A comparative study of the mass transfer kinetics of metal biosorption by microbial biomass. Hydrometallurgy 1999, 52, 189-197. [CrossRef]

46. Lagergren, S.K. About the theory of so-called adsorption of soluble substances. Sven. Vetensk. Handingarl 1898, 24, 1-39.

47. Khamizov, R.K.; Sveshnikova, D.; Kucherova, A.; Sinyaeva, L. Kinetic model of batch sorption processes: Comparing calculated and experimental data. Russ. J. Phys. Chem. A 2018, 92, 2032-2038. [CrossRef]

48. Komy, Z.R.; Shaker, A.M.; Heggy, S.E.; El-Sayed, M.E. Kinetic study for copper adsorption onto soil minerals in the absence and presence of humic acid. Chemosphere 2014, 99, 117-124. [CrossRef] [PubMed]

(C) 2020 by the authors. Licensee MDPI, Basel, Switzerland. This article is an open access article distributed under the terms and conditions of the Creative Commons Attribution (CC BY) license (http://creativecommons.org/licenses/by/4.0/). 